\title{
LA NOVELA ACTUAL Y EL CAMBIO DE CICLO HISTÓRICO
}

\author{
José María POZUELO YVANCOS \\ Universidad de Murcia
}

U

na lectura del ensayo de Francis Fukuyama titulado El fin de la Historia y el último hombre, ${ }^{1}$ que desarrolla su breve y polémico artículo parcialmente del mismo título, publicado en verano de 1989, no puede justificar, ni por la fortaleza de ideas ni por densidad argumentativa, el relieve que ha obtenido. En este caso se produce uno de esos fenómenos que dan lugar al éxito de los eslóganes: su fortuna está directamente vinculada a la forma, y a un estado de cosas que los hace eficaces. La forma es clara: el fin de la Historia es un sintagma eficaz, pronunciado en los albores de un fin de siglo y coincidiendo con un estado de cosas político y cultural que lo hacía, si no necesario, sí contundente. Es un sintagma que en el artículo original de 1989 adoptaba una modalidad interrogativa -se acababa de producir el derrumbe del muro de Berlín- y sin embargo ve suprimida la interrogación en la versión del libro. La inseguridad de partida respecto al diagnóstico se convierte, una vez obtenido un cierto relieve público y una confirmación política del cambio, en la seguridad de la constatación.

Francis Fukuyama se preguntaba en ese artículo si la caída del muro de Berlín, el fin del comunismo y de ciertas dictaduras latinoamericanas de origen neofascista, como la chilena o la argentina, no suponía el triunfo definitivo de la democracia liberal, y por tanto el final del ciclo abierto por la Filosofía de la Historia de Hegel y continuado por Carlos Marx. Fukuyama no hacía otra cosa, en un contexto conservador (el origen del artículo fue una conferencia pronunciada en la Universidad de Chicago y Fukuyama fue invitado por el pensador Allan Bloom, uno de los abanderados ideológicos de la era Reagan) que proclamar el triunfo del neocapitalismo como sostén de las estructuras políticas y, por tanto, el fin del enfrentamiento entre los bloques, por la hegemonía indiscutible de uno de ellos. Por supuesto, esa foto interesada políticamente significaba que no habría alternativa y que el status $q u o$ de dominio de la superpotencia americana era el punto de llegada del convulso siglo XX.

Pero un eslogan como el fin de la Historia no habría tenido éxito si no respondiera a un sentimiento real vivido por diferentes estadios de la cultura, propensos a considerar que a finales del

\footnotetext{
${ }^{1}$ En el capítulo dedicado a Fukuyama dentro de un libro titulado Los fines de la historia Perry Anderson (1996:113) 1lega a lamentar esa extensión desde el artículo al libro, porque le obligó a un salto mucho menos convincente.
} 
siglo XX, y merced a la decisiva caída del mito alternativo al mito del bienestar capitalista, no estábamos realmente ante un estado de cosas susceptible de ser mirado también como un estado del pensamiento y de la cultura, que podía verse refrendado por otros ensayos nacidos en contextos sociológicos y culturales diversos y menos directamente comprometidos con el pensamiento político neoliberal, algunos de los cuales abordaré de inmediato, y lo que a nosotros interesa, por una literatura narrativa, que vendría a adoptar en la jerarquía de sus contenidos y en ciertas formas en la que se vierte, un diagnóstico que, si bien no se adapta por completo a la naturaleza interesada políticamente del fin de la Historia, sí afronta temática y formalmente lo que podríamos llamar un fin de ciclo, un balance de la historia reciente hecho desde el presente narrativo, desde la novela actual.

Lo que me propongo abordar en esta conferencia es el dibujo que del fin de ciclo histórico hace la novela actual española, dibujo que por una lado conecta con el estado de cosas y pensamiento que traducen ciertos ensayos inmediatamente anteriores de la sociología cultural europea, y por otro lado adopta muy particulares concreciones referidas al caso concreto del contexto sociopolítico y cultural español, cuyo ciclo histórico, que tiene su anclaje fundamental en la denominada Transición, es evaluado, visitado críticamente, en tonos que van desde la reflexión y la nostalgia a la crítica agraz, por un conjunto de novelas publicadas en el quicio del siglo XXI, y en los primeros años del actual milenio, la mayor parte de ellas proclives a hacer un balance de época, que puede también considerarse balance generacional de novelistas cuya juventud coincide con los últimos años de la dictadura de Franco, y que veinticinco años después, están en condiciones de tematizar resultados reales de esperanzas reales.

Me sitúo por tanto ante un tipo especial del subgénero de la novela histórica, aquélla en la que la historia no es recorrida siempre en sus hitos secuenciales, ni en el orden de su cursus cronológico, sino como mito epocal reconstruido desde el presente, y enfrentado a él. Mi interés radica no tanto en cómo se ha novelado la Transición política española en novelas directamente históricas, sino en cómo es evaluada en la construcción del mito revolucionario que anidaba en las esperanzas generacionales de quienes eran jóvenes cuando Franco murió, y en el balance que hacen, en el quicio del siglo XXI, de tales esperanzas. Considero que no puede ser casual que en tan sólo cinco años se hayan publicado en España una serie de novelas directamente comprometidas con esta temática. Las seis novelas seleccionadas no son las únicas en las que puede quedar reflejado el punto de vista enunciado, aunque espero que sí sean suficientemente representativas para el balance que me propongo hacer. Enumero aquéllas en las que me detendré: de David Castillo, El cielo del infierno (Barcelona, Anagrama, 1999), de Alejandro Gándara, Últimas noticias de nuestro mundo (Anagrama, Premio Herralde de 2001), de Rafael Chirbes, Los viejos amigos (Barcelona, Anagrama, 2003), de J.A. González Sainz, Volver al mundo (Barcelona, Anagrama, 2003), de Almudena Grandes, Castillos de cartón (Barcelona, Tusquets, 2004) y de Bernardo Atxaga, El hijo del acordeonista (Madrid, Alfaguara, 2004).

El ensayo de Jean-François Lyotard, titulado La condición posmoderna. Informe sobre el saber fue, como su subtítulo advierte, un informe encargado por el Conseil des Universités del gobierno de Quebec y con unas perspectivas y tono muy distintos a los de Fukuyama, pero no alejados de sus 
conclusiones. Acertó Lyotard a revelar una condición de época, dando un sentido epistemológico fuerte al muy ambiguo y evanescente adjetivo de posmoderno, adjetivo que entonces tan sólo se aplicaba a ciertas formas de la arquitectura contemporánea, las teorizadas y llevadas a la práctica por Robert Venturi. Lyotard enfrentó dos formas de saber, entendiendo como saber el que se ha legitimado por una práctica de conocimiento y por una administración del poder: la premoderna, que reproducen los relatos populares, y que se instala en un universo donde el tiempo es reversible o en cierta medida eliminado como historia al definirse desde el rol que asumen los participantes del acto linguístico de la narración (el narrador y el oyente actualizan los roles históricos y los llevan a un presente continuo, recurrente y en cierta medida a un tiempo mítico), y el saber moderno que es un saber no circular sino proyectivo, ligado a la ciencia y al Estado y que se elabora en relación con una praxis (léase reificación) externa al propio saber.

Lo que ocurre según Lyotard es que el saber moderno ha ideado un mecanismo narrativo de legitimación del conocimiento, construyendo un vínculo estrecho entre la actividad lingüística constatativa y la ética, entre el acto de lenguaje de la afirmación y el performativo (el actuar), y esa necesidad ha llevado a la construcción de metanarraciones legitimadoras morales del conocimiento (el deber) proyectando éste en un sentido de progreso, de historia, de camino. Frente a estos dos modelos Lyotard contrapone el que define como actual, y a partir de una lectura de Musil (1984: 36), y del concepto de desrelición de sí mismo, llega a un tipo de conocimiento que se ha atomizado, precisamente porque han caído en descrédito las legitimaciones modernas del saber. Los grandes relatos y sus metanarraciones legitimadoras como el de la emancipación hegeliana del Espíritu o el marxista de la emancipación histórica del proletariado, que suponían en todo caso un universalismo que totalizaba un proyecto compartido, común, han finalizado. Lyotard explícitamente cita el comienzo de las deslegitimaciones en el seno de la literatura y el arte. A Musil se unen Krauss, Hofmannstal, Broch, pero enseguida Wittgenstein, Mach (1984: 78). Al final de su ensayo llega incluso a lanzar, revestido del parapeto de las nuevas autoridades sin disimulo una andanada a Habermas y su teoría del consenso comunicativo.

Estamos en 1979 y en vísperas de que Habermas pronunciara su famosa conferencia contra la posmodernidad, precisamente, que tituló: «El dios Moderno: un proyecto inacabado» ${ }^{2}$, y en la que el último representante de la Escuela de Frankfurt pusiera en el mismo saco a todos los que denominó «neoconservadores» desde Foucault y Derrida hasta los discípulos de Nietzsche y Heidegger. No podemos entrar en el debate que siguió entre Lyotard y Habermas (Anderson, 1998), pero a los efectos que aquí nos interesan sí destacar que Habermas en su radical andanada contra los «jóvenes conservadores» sí se da cuenta de que él mismo está siendo el último representante de la Filosofía de la Ilustración, en un contexto en el que ese Gran Relato (Habermas no lo llama así, obviamente) se ha

\footnotetext{
2 «Dios Moderne: Ein unvollendetes Projekt». Fue conferencia pronunciada en 1980 por Habermas al recibir el Premio Adorno de la ciudad de Frankfurt. La versión inglesa se publicó en 1981 con el título de «Modernity versus Postmodernity». La versión española se ha titulado «La modernidad, un proyecto incompleto», en Hal Foster, ed: La posmodernidad. Barcelona, Kairós, 1998, pp.19-36, ha elegido el adjetivo «incompleto», aunque creo mejor el de «inacabado», porque lo veo más fiel al sentido dado por Habermas (ocurre lo mismo con la sinfonía 8 de Schubert).
} 
desmembrado. Lyotard acierta en la denominación de «pequeños relatos» para las formas que toman hoy tanto la invención imaginativa como la ciencia desde el principio de indeterminación de Heisenberg (Lyotard, 1984: 109) y se acerca todavía más Ihab Hassan, tratando del concepto literario de posmodenidad como The dismemberment of Orpheus. Al final acierta quien da con una buena metáfora que reúna en una imagen suficientemente expresiva ese aire de época o condición para el que Gilles Lipovetsky elige la metonimia del vacío, en su conocido diagnóstico titulado así: La era del vacío. Ensayos sobre el individualismo contemporáneo, cuya edición original es de 1983. La de Lipovetsky adeuda mucho, hasta convertirse prácticamente en una glosa, a la descrita por Daniel Bell (1976) en su análisis de la sociedad post-industrial y la nueva estética del consumo hedonista que este sociólogo adopta como eje articulador de la posmodernidad y que Lipovetsky va glosando en las muchas formas que dibuja la banalidad, el individualismo feroz, el relieve de lo contingente y un cierto sentido de asimilación hedonista de las fuerzas revolucionaria o transgresora. La masa cultural ha institucionalizado, dice Lipovetsky la rebelión modernista (1983: 105). La vanguardia no sólo no suscita indignación, sino que las formas de la innovación estética se convierten en los nuevos parámetros del consumo masivo que no sólo legitima las prácticas transgresoras sino que subvierte su sentido al convertirlas en homenaje-parodia, pastiche, remake.

La sociedad post-industrial, advierte Daniel Bell, ha generado la uniformización cultural por la vía de superar, hasta anularlo, el divorcio entre los valores de la esfera artística y los valores cotidianos. La moda eleva a objeto estético las anteriores transgresiones y comercia con ellas, incluso el ecologismo y sus valores alternativos se convierten en un lugar para la identificación. La lógica del modernismo, que era la de un arte hecho de rupturas de las normas victorianas, no tiene continuidad posible, las negaciones del arte vanguardista son reescritas como repeticiones rituales de la retórica de la transgresión.

La idea de retórica, de pastiche, el propio sentido de la parodia que a Linda Hutcheon sirvió como divisa del Posmodernismo, están anunciando una dinámica de agotamiento del gesto vanguardista, que es el punto común que une las descripciones de Iahb Hassan, John Barth y Umberto Eco, no por su extremosidad, sino por el cambio de su sentido y de su valor. Las grandes negaciones de antaño suscitan en los museos las colas de gentes que rinden culto masivo al gesto de la ruptura, convertido ahora en objeto de culto por la sociedad que los motivó y respecto de la cual nacieron como elementos transgresores. Escribe Gilles Lipovetsky:

La edad posmoderna, en ese sentido, no es en absoluto la edad paroxística libidinal y pulsional del modernismo; más bien sería al revés, el tiempo posmoderno es la fase cool y desencantada del modernismo, la tendencia a la humanización a medida de la sociedad, el desarrollo de las estructuras fluidas moduladas en función del individuo y sus deseos, la neutralización de los conflictos de clase, la disipación del imaginario revolucionario, la desubstanciación narcisista, la reinvestidura cool del pasado. El posmodernismo es el proceso y el momento histórico en que se opera ese cambio de tendencia en provecho del proceso de personalización (1983: 113).

En parecidos términos, valora la «personalización» dominante en el modernismo el teórico español de Estética Simón Marchán-Fiz quien afirma: 
La lógica superior del proyecto ha sido sustituida por la de 'mi propia realidad': el deber del arte como moral del imperativo categórico ha sido sustituido por el arte como voluntad de vida; las expectativas emancipatorias parecen abandonar el macrosujeto revolucionario y recluirse en lo microsocial, la clausura o contracción de futuro refuerza el presente histórico o el pasado. El recortar o el abandonar sin más las expectativas destila un escepticismo y amoralismo... resignación, nihilismo histórico, decepción respecto a los ideales de las viejas vanguardias... (1986: 304).

Aunque deudatario de la inserción histórica de Daniell Bell, Lipovetsky no acababa de decidirse, como se ve al final del texto arriba citado, entre considerar el posmodernismo como un momento (el de la sociedad post-industrial) o un proceso que actúa como culminación extremada del modernismo. En toda la bibliografía sobre la cuestión encontramos esta indeterminación, ya presente en Hassan, en Barth, en Eco, poco favorecedora del compromiso con una visión histórico-social. Eso ha hecho que Vance Holloway llegue a hablar de dos posmodernismos: el de Lyotard y Jameson por un lado y el de Barth, Eco, Hutcheon y Brian Mac Hale (Holloway, 1999: 41 y ss), por otro, en una distribución que tiene el inconveniente de la facilidad de situar la perspectiva sociológica y la literario artística como pivotes diferenciadores de uno y otro.

Por eso me parece especialmente importante y con razón es situado por Perry Anderson en Los orígenes del posmodernismo como piedra angular de una visión integral, global, del fenómeno, la que aportó Frederic Jameson en su libro de 1984 El posmodernismo o la lógica cultural del capitalismo avanzado. La principal virtud de Jameson es no haber provocado una escisión entre la sociología política y económica del que llama «capitalismo tardío (o avanzado) (late) y las manifestaciones artísiticas y culturales que conocemos como posmodernas, tanto en la arquitectura (la descripción del edificio del Hotel Bonaventura), la pintura (es conocida la comparación dialéctica que hace en todo un capítulo entre las botas de van Gogh el cuadro «los zapatos de labriego» y el de Andy Warhol «Daimond Dust Shoes» («Zapatos de polvo de diamante») etc. La idea es dar con una pauta cultural de raíces universalistas, que responda a la lógica de un cambio notable en los sistemas de producción y de consumo en el capitalismo tardío, que son muy novedosos respecto a los que vivió la sociedad industrial del primer y segundo capitalismo, y que es la que ha generado un cambio profundo en los valores culturales dominantes, y en la propia identidad del fenómeno artístico.

Desde una posición ideológica muy diferente, Jameson tiene un punto de partida semejante al de Daniel Bell: el diagnóstico de que con el pop art y la alianza que establece con la industria (que es la estructura más visible del posmodernismo) ha triunfado un populismo estético que ha modificado la pauta cultural dominante. Esta modificación no nace únicamente en el seno de la lógica evolución de los sistemas artísticos, sino que tiene que verse en relación con la sociedad de la información, sociedad del consumo o sociedad de los media. En este sentido, Jameson es bastante deudatario, me parece, del concepto de simulacro de Baudrillard. Pero dejaré a un lado esa conexión, por el momento. Lo que ahora nos interesa del razonamiento de Jameson es que el mercado ha hecho mercado del repudio del mercado que los movimientos vanguardistas habrían convertido en su divisa. El ethos alternativo, inmoral o provocador que situaba al arte como «conciencia crítica» (en relación con su medida «distancia crítica» respecto a los valores de la sociedad burguesa), ethos que había generado la dinámica de la innovación , del permanente despliegue hacia un más allá, a lo nuevo, lo moderno, lo 
joven, lo rupturista, es la fuerza que el capitalismo tardío convierte en propia: la constante innovación, el reciclaje, la ruptura de la distancia crítica con la industria (los botes de tomates Campbell, o los póster de la iconografía publicitaria son emblema del nuevo arte), que ha roto la línea divisoria entre estética y consumo, convirtiendo el consumo mismo de lo novedoso y lo alternativo (por ejemplo el ecologismo) en un acto estético. El ecologismo y lo sostenible se convierte en divisa del nuevo mercado y el turismo se lanza a explotar lo inexplotado; apoyado en la falta de culpa respecto a la depredación del medio, objetivo que fue de un «capitalismo no avanzado».

Pero más importante aún que este punto de partida me parece la relación que Jameson llega a establecer entre la cultura del capitalismo avanzado y la nueva superficialidad que se encuentra en la teoría de la imagen y el simulacro (sustitutivos de la referencia), la primacía de los vehículos de reproducción como el ordenador (máquina de re-producción que ha sustituido a las maquinas productivas) también, y esto es lo que nos afecta de lleno para el objeto de esta ponencia, el consiguiente debilitamiento de la historicidad, tanto en nuestras relaciones con la historia oficial, como en las nuevas formas de la temporalidad privada, dando lugar a un «sujeto emocional» en cierta medida nostálgico, propenso a considerarse más allá de la historia, mensurables estos procesos en la importancia que adquiere la autosatisfacción, la higiene propia, salud o forma corporal, y espiritual, ahí el arte, que ya no tiene la necesidad de situarse en una «distancia crítica» respecto a los valores predominantes en la burguesía consumidora posmoderna. Conceptos tales como «angustia», «alienación», las experiencias que corresponden con el cuadro El grito de Munch, han periclitado; no sólo porque los cuadros de Warhol sean de Marylin o Elvis (o los botes de Coca-Cola) (Jameson, 1991: 36) sino porque se ha eliminado la conciencia separadora entre sociedad de consumo y valor artístico. La idea más poderosa es la de simulacro: la cultura de la imagen se ha convertido en la forma final de la reificación mercantil (Jameson, 1991: 45).

En las novelas españolas que de inmediato analizaremos puede percibirse una representación de lo que Jameson, analizando la película American Graffiti, ha llamado la «moda nostalgia» como intento de recobrar la ya perdida era Eisenhower y los movimientos culturales del rock and roll, pandillas juveniles, etc. Hay según Jameson una incompatibilidad entre esta moda retro de la nostalgia posmodernista y la historicidad genuina. Hay una colonización del presente por las modas de la nostalgia, que ni por el teñido de sus imágenes ni por el proceso de idealización al que aquéllas impregnan tiene nada que ver con la historia como tal. El ejemplo de Raghtime o Chinatown es analizado como emblemático de tal estética, falsamente histórica pues no sólo elabora el pasado desde las necesidades del presente, sino que elude preguntarse por la historia real y los referentes históricos, sustituidos por su estereotipo más visible, cuando parece haberse producido, si no el fin de la historia, sí el fin de aquella historia revolucionaria de los sucesivos modernismos.

No soy proclive a establecer directas conexiones entre conceptos culturales y novelas concretas, salvo que la contundencia de una estructura, bien temática o bien formal en un período de tiempo muy breve, y su reiteración en escritores que no parecen tener comunicación entre sí, suscite la pregunta acerca de tal conexión. Me propongo trazar un puente entre esta estética de fin de ciclo que ha dibujado 
la sociología posmoderna y un conjunto de novelas que no me atrevería a calificar propiamente como posmodernas en cuanto a su factura, pero sí han tematizado y adoptado la forma de clausura y evaluación de un ciclo histórico, que es una de las divisas constantemente reiteradas en la bibliografía posmodernista. Advierto que posiblemente sus autores negarían formar parte de la cultura de la posmodernidad, porque las novelas seleccionadas y en general la literatura española, salvo para casos como los de Félix de Azúa, Javier Marías, Vicente Molina Foix o Enrique Vila Matas, no suele elevar a autoconciencia los procesos posmodernos, y en las novelas que he seleccionado no es condición de su forma la protuberancia y evidencia del gesto, que sería una condición necesaria para una conciencia posmoderna. Pero que no se inscriban como conciencias explícitas no significa que no participen, como pretendo hacer ver, de un «espíritu de época» que entiende la actualidad presente como el fin liquidatorio de un proceso, léase éste como ideología marxista, anarquista o simplemente las ilusiones concebidas en la Transición política española con la muerte de Franco.

Las enumeradas, de David Castillo: El cielo del infierno (Barcelona, Anagrama, 1999), Alejandro Gándara: Últimas noticias de nuestro mundo (Anagrama, Premio Herralde de 2001), Rafael Chirbes: Los viejos amigos ( Barcelona, Anagrama, 2003), J.A. González Sainz: Volver al mundo (Barcelona, Anagrama, 2003); Almudena Grandes: Castillos de cartón (Barcelona, Tusquets, 2004), Bernardo Atxaga: El hijo del acordeonista (Madrid, Alfaguara, 2004) ${ }^{3}$, abarcan por tanto un período muy corto de tiempo, la más antigua de las consideradas, la de David Castillo es de 1999 en su edición catalana, pero se publicó en castellano en 2001; la más reciente es la de Bernardo Atxaga que, en el momento de escribir estas líneas (octubre de 2004) lleva tan sólo un mes en las librerías. Apenas cuatro años para el lector en castellano han proporcionado seis novelas en las que se hace, de distinta manera en cuanto a formato y tono, pero de muy semejante manera en cuanto a estructura temática e incluso formal (en el contexto de forma que luego explicaré), una crítica de las derivaciones finales de unas ilusiones históricas, que los personajes de tales novelas ven ya cerradas, bien siguiendo la estructura del desencanto, bien de la nostalgia, bien del balance crítico, pero en todo caso una estructura de la memoria que tiene a la militancia comunista o ácrata como punto de partida y al individualismo burgués-desencantado y consumista como punto de llegada, como si estas novelas quisieran confirmar en su trazado temático y en su estructura formal, ese «final de ciclo» histórico descrito por la bibliografía de la sociología de la cultura y cuya síntesis he antepuesto en la primera parte de mi ponencia.

Las seis novelas elegidas, que son tomadas aquí en tanto pueden ser representativas de un acento muy concreto de la visión del presente histórico en la novela española de los últimos años, coinciden como digo en esta estructura de cierre de ciclo histórico, tanto por lo que los personajes o el narrador enuncian, cuanto por la forma de memorialismo o balance que a posteriori de los hechos adoptan respecto a las ilusiones alimentadas en la militancia antifranquista o en los primeros años de la transición. No son las únicas en que este tema se da, puesto que de modo lateral el del desencanto político es tema que podremos encontrar esbozado en otros lugares, por ejemplo en la novela de J. A.

\footnotetext{
${ }^{3}$ Las citas las haré en el texto siempre según las ediciones señaladas.
} 
Bueno Alvarez: El último viaje de Eliseo Guzmán (Alfaguara, 2001, que fue Premio Andalucía de novela) donde encontramos que los dos hijos del protagonista, que saldan las cuentas con él en vísperas de su muerte, son un viejo militante de izquierdas, ya muy desengañado, y su contrapunto, el ejecutivo pequeño burgués, las dos vías de salida para la vieja militancia de los jóvenes del franquismo que en esta novela representa emblemáticamente el patriarcal Eliseo Guzmán.

Por lo mismo, la novela de Mariano Antolín Rato titulada Fuga en espejo (Alianza, 2002) contiene las reflexiones de un escritor llamado Rafael Lobo quien enuncia así la poética narrativa de la novela que está escribiendo:

\footnotetext{
He tratado de penetrar en ellas la caótica diversidad de unas vidas que terminan por adquirir la lógica del destino...pero me he esforzado por no hacer lo que otros escritores, que no le dejan al futuro nada, excepto que los personajes se plieguen a ese destino. Asumo que estamos en la fase terminal de una época, los seres vagamos entre dos mundos, uno muerto y el otro incapaz de nacer y ya no existe ninguna razón para escribir de modo noble, moderno o desde cualquier otro punto de vista más complejo. Sólo me impulsa el deseo de escribir. Quizá con objeto de olvidarme de mí mismo, de seguir huyendo (2002: 37).
}

Palabras con que Mariano Antolín Rato, uno de los pocos escritores que han continuado la herencia de la modernidad en el compromiso de su propia escritura, sanciona el momento que, de una forma lateral, ya digo, está presente en muchas novelas, pero que en las seis elegidas adquiere la condición de eje dominante de su estructura y de su sentido.

La novela Últimas noticias de nuestro mundo de Alejandro Gándara, Premio Herralde de 2001, está directamente referida en su ambientación a la caída del muro de Berlín como datación concreta de ese fin de ciclo histórico e indirectamente metaforiza el desconcierto y sinsentido que alcanza a unos espías del extinto bloque comunista que esperan unas señales que no llegan. La novela de espionaje ha tenido siempre, en las mejores realizaciones del género, una línea interna, un lugar impreciso donde el espía, que ejecuta planes cuyo sentido último desconoce, puede preguntarse alguna vez por ese sentido, por su posición en la trama. Asomó ese lugar en el Graham Greene de El tercer hombre y más desarrollado en El factor humano. El mejor John Le Carré ha imaginado en su personaje George Smiley una lucidez desengañada. Pero eran atisbos, sugerencias nacidas en un tiempo histórico, conocido como guerra fría, en que todo estaba en su lugar, comunismo y capitalismo, buenos y malos, claramente diferenciados en el escenario y en los sucesos. ¿Qué puede ocurrirles a unos espías alemanes de la Antigua República Democrática, la Alemania del Este, después de la caída del muro? Con esa caída se desmoronaron muchas cosas, pero también hubo el derrumbe del sentido de la Historia para quienes habían servido en la Stasi y los servicios de información de la Alemania comunista y de la Rusia anterior a Gorbachov.

Gándara nos ofrece una excelente trama, que discurre por dos vías paralelas que por momentos se entreveran: las acciones de los protagonistas, entregados a los laberintos de sus búsquedas, de sus persecuciones, vigilancias y ocultaciones, y el laberinto menos fácil de sus dudas, de su propia condena a una actividad que es ya sólo la sombra de una historia que tuvo un sentido y que ahora se espera o se necesita que continúe teniéndolo de alguna forma. Todos los personajes de su trama, por supuesto los dos protagonistas, Anja y Walter Bauss, pero también los personajes secundarios, que asoman a 
sus vidas, esperan algo, como siempre hizo todo espía , una señal, una orden, la confirmación de que su sentido en la Historia no ha acabado. Toda la novela mide el compás de esa espera, pero como le ocurre a los personajes del drama de Beckett, en esa espera sólo hay pasado y presente, indagaciones rutinarias o peligros reales y la intuición de que el final ya se produjo y ellos pueden estar ahí como restos deslavazados de una obra sin futuro posible. Gándara ha narrado la historia de unos espías el día después, cuando todos se han marchado y han quedado los retazos de un juego, la música cansina de una fiesta ya concluida. No hay por tanto postulación metafísica, sino territorios externos e internos recorridos al paso de sus protagonistas, y con la misma carencia de sentido de ellos. Esta manera de que el género, en la realización de una trabada estructura externa, sirva a una estructura simbólica mayor. Los diálogos suplen lo que el narrador ha evitado ofrecer, al renunciar a toda omnisciencia, y los personajes han de ir diciendo ellos mismos sus dudas y conjeturas. Gándara maneja la dosificación informativa del diálogo porque todo lo que los personajes dicen revela y oculta información al mismo tiempo; hay silencios, disfraces, y movimientos no explicados. Las elipsis, los saltos van componiendo la otra nota estilística que afecta al conjunto de la novela: la intriga muy bien tramada, servida por pequeños detalles, persecuciones (como la formidablemente narrada que Anja hace de Juan), pistas que se continúan, y que van atrapando al lector en la red tupida de un mundo que espera su sentido.

David Castillo hace en su novela El cielo del infierno (1999) un ajuste de cuentas con toda una época, la de la insurrección anarquista de grupúsculos catalanes en la transición española de 1977 a 1978, pero también con un ambiente y formas de vida de activistas jóvenes que tenían por entonces veinte años y militaban en grupos derivados del sueño anarquista y la resistencia antifranquista. Su personaje protagonista, Dani, guiado tanto por un desengaño político como por el instinto de autodestrucción al que le somete el consumo de droga, camina en una circularidad inevitable y fatal hacia su crisis existencial.

La novela de Castillo propone de ese modo un salto desde la anécdota personal a la sociopolítica, unidas en la biografía de este activista político, primeramente militante comunista y después integrante de los comandos autónomos anarquistas. La escalofriante escena del comienzo, que narra la lucha entre un gato y una rata en una desolada ruina, la bien administrada descripción de las revueltas callejeras contra la policía en el Paralelo, las soberbias páginas con que se inicia la segunda parte, en las que la novela se abre a las pesadillas alucinatorias escritas con un prosa fulgurante, permiten que la novela deslice constantemente el fin del ciclo histórico hacia los espacios sin salida de una crisis personal en que la droga (que actúa como el cielo de ese infierno que recoge el título), solamente es el contrapunto del otro muro, el de la historia de un ideal fracasado políticamente, sin sentido, descolgado de su origen, contra el que chocan el protagonista y su novia, Maite, entregada antes que él a la autodestrucción.

La historia se narra en tres partes; la primera transcurre en la cárcel, y reúne un desarrollo bien pautado de la rutina cotidiana con incursiones del protagonista en su propia historia anterior y valoraciones sobre lo que observa y vive en la prisión. Aunque está narrada por un narrador omnisciente, ha sido un acierto la focalización interna, puesto que es Dani quien lleva la perspectiva, 
lo que permite reunir junto a la descripciones de los tipos carcelarios con sus dosis realistas de brutalidad y corrupción (un tanto tópicas, hay que decirlo) valoraciones propias que trazan ya un puente con el que será luego el motivo central de la novela: no hay ideal posible que pueda sostenerse entre esas paredes carcelarias, pero tampoco lo hay ya para su historia personal y colectiva.

Sobreviene así el que será el nudo central que explicará el desarrollo de la segunda parte: la visión antiheroica de la realidad, pues Dani somete su situación a una perspectiva degradante sin concesión alguna al heroísmo y con una valoración muy agria de los protagonistas de la lucha política en esos grupos de ultraizquierda. Tal visión alcanza asimismo a la propia realidad del exilio anarquista, dibujada aquí con trazos gruesos, muy poco proclives a la idealización heroica con que los han nutrido otros novelistas y quizá más fácil de sostener como perspectiva individual del protagonista, porque la novela no sobrevuela casi nunca perspectivas históricas, o visiones de conjunto, sino los hechos descarnados de una derrota personal que quiere ser saldo de una aventura colectiva, salto generalizador no exento de riesgos, e injusto según se mira a verdaderas biografías de exiliados tejidas de un heroísmo real. Es afortunada la llave que da entrada a la segunda parte, la evocación del asesinato de John Lennon, en la medida en que emblematiza el fin de una época. La novela incluye una tercera parte, con un quiebro hacia los episodios que transcurren en la Nicaragua sandinista, y los diferentes motivos de acción rápida, entre detectivescos y bélicos que la forman. Se ve en esta salida última de la novela muy bien el didactismo que ha podido llevar al autor a cerrar la salida colectiva del falso heroísmo de la revolución sandinista, sometida por el narrador a igual proceso de destrucción interna. David Castillo ha querido cerrar del todo una parábola moral sobre las revoluciones perdidas.

Si las de Gándara y Castillo habían acertado, con ejemplos concretos tomados de la Historia (guerra fría, revolución sandinista), a tematizar simbólicamente el fin de la Historia que había mantenido todo el entramado político europeo y los mitos de resistencia de una generación, llevados desde el anarquismo juvenil hasta el último brote de la Revolución sandinista, donde se muestra más visible la pregunta de un sentido histórico en la construcción del presente, esto es la pauta de cierre de ciclo como trayectoria memorialística personal, es en dos novelas de 2003 muy semejantes en alcance y sentido (incluso en la estructura dialogística que adopta su factura formal). Me refiero a las novelas Los viejos amigos de Rafael Chirbes y Volver al mundo de J. A. González Sainz.

Rafael Chirbes, como saben sus fieles lectores, da un paso, con cada novela suya, en el sentido de una misma dirección: la de narrar en forma testimonial y moral la historia de los españoles desde la posguerra al día de hoy. Su voz narrativa y su posición literaria adquieren dimensiones memorialísticas en la medida en que quiere rescatar del olvido episodios de tres generaciones de españoles, pero no se resiste a la sola dimensión realista, que quiere sobrepasar por la vía de ofrecerse como testigo moral y en cierto modo elegiaco, lo que en esta novela es muy evidente, de los sueños caídos de una generación de españoles que coincide con la suya. Los viejos amigos (2003) es novela desembocadura de un río que había discurrido en las dos novelas suyas anteriores, La larga marcha (1996) y La caída de Madrid (2000) por la historia política y social de la posguerra y la transición que se inicia con la muerte de 
Franco y forma con ellas el final de lo que podría considerarse temática y estilísticamente como una trilogía.

Hablo de desembocadura y final de trilogía porque lo que diferencia esta novela de las anteriores no es solamente que haya llevado la radiografía moral hasta los años actuales, sino, sobre todo, que aquí se impone ya una visión de fin de ciclo, desengañado respecto a una historia colectiva que en aquellas novelas había ofrecido como crónica y ahora es directamente un ajuste de cuentas, como si Chirbes quisiera dar cima a su ciclo aprestándose a recoger los restos del naufragio. La navegación eran, otra vez, los ideales revolucionarios que anidaron en una generación de militantes comunistas, entonces jóvenes y ahora ya en la cincuentena, con todo su catálogo de mitos y actitudes que fueron individuales, pero que fueron sobre todo — de ahí su raigambre mítica - colectivos, y que son enfrentados en esta novela a la agria constatación de un fracaso generacional que se reza aquí en el rosario de paralelos fracasos individuales, que afectan a todos los órdenes de sus personajes, familiares, políticos, de pareja, y culturales en su sentido amplio.

La urdimbre narrativa de Los viejos amigos se desarrolla a partir de una cena ideada por uno de los personajes, que consigue reunir en torno a una mesa a los miembros de una antigua célula comunista, treinta años después de aquella aventura revolucionaria, que tampoco fue demasiado, y que se desarrolló mucho más en ideales, proclamas, posters del Che, reuniones, alguna escaramuza con la policía en la Universidad y, por supuesto, todo un abanico de señas de identidad colectiva en hábitos sexuales, lecturas, referencias políticas y que Chirbes convierte sin piedad alguna en máscara de un fetiche. Bastaría con leer el menú de la «Cena aniversario de los viejos camaradas» (2003: 133) y la atmósfera posmoderna en que se desarrolla para que quedase grabada la imagen de un sarcasmo.

La novela va recorriendo una perspectiva múltiple en primera persona narrativa con varios narradores que se van alternado y que son algunos de los comensales; se recoge, narrada por ellos mismos, la que fue su vida anterior y su contraste con lo que es ahora y, en suma, las peripecias del tránsito de una a otra. Ese artificio narrativo permite recorrer todos los tipos humanos y situaciones, especialmente la gama variada en tonos de una misma melodía hecha de renuncias y traiciones, para lo cual la estructura favorece siempre una actitud de contraste entre el ayer y el hoy.

Tal estructura permite ofrecer de modo reticular, como un mosaico, toda una historia colectiva, que logra de este modo trazar una historia sin venir plegada a la mera sucesión cronológica ni tampoco a la sola perspectiva de un narrador, lo que habría resultado lineal. Puede que la intención de Chirbes haya sido que los lectores vieran que cada celdilla de esta célula comunista es finalmente la suerte de un mismo camino, el de las traiciones que cada uno ha desarrollado, porque no se salva casi nadie. Bueno, puede decirse que se salva el único personaje que no tuvo aquellos ideales y que se limito a vivir sin coartadas ideológicas. La novela es tremenda en sus juicios, y al hacer coincidir el arco del desengaño político con la propia curva de la edad, desde la juventud hasta la madurez, cada historia se ve como ejemplo de una caída personal, que Chirbes, esta vez, ha querido que fuera ejemplar.

La protagonista de Los viejos amigos es toda una generación: la burguesía que ahora sobrepasa los cincuenta años, y que es la que Chirbes enfrenta aquí al espejo de sus miserias. Vivió esa generación 
en los años gloriosos de su «revolución pendiente» muchos ritos y mitos, que los lectores de esa edad reconocen de inmediato: de Baudelaire, leído como poeta revolucionario, a Mao, la Joven Guardia Roja, la Liga, liberaciones sexuales, posters del Che, un Guernica en la sala de estar del piso de Malasaña o Argüelles. Pero también, un poco antes, una infancia del tebeo del Capitán Trueno y el Jabato, celtas cortos (una marca de tabaco, no un grupo musical, entonces), bisontes (otra marca). La novela va desde aquellos mitos a las realidades de hoy: sida, parejas rotas, especulaciones inmobiliarias, y un cierto aire de ruina, hecha de los jirones de aquellos mitos, convertidos ahora en rutinas y rencores de la Historia. Como si fuera un saldo.

Curiosamente, en el mismo año y sello editorial se publica la extensa y ambiciosa novela de J. A. González Sainz: Volver al mundo. La curiosidad viene de la semejanza estructural: la trayectoria, mitos y desengaños de un grupo de amigos progres y revolucionarios, es evaluada años después en conversaciones con alguno de sus supervivientes, en el escenario rural de un paraje de Soria, adonde acude Bertha, una traductora vienesa, quien busca explicarse las razones y circunstancias de la muerte de Miguel, su amante. Toda la novela está quiciada formalmente sobre las conversaciones de Bertha con Anastasio (un campesino amigo de Miguel) y con Julio, amigo y compañero de Miguel en sus lides políticas juveniles, quien le acompaña a Madrid y milita con él en un grupo subversivo terrorista de raíz anarquista, guiado por la cerril ideología estalinista de Ruiz de Pablo. La trama de la investigación que sostiene el misterio de la muerte de Miguel alcanza a ser una trama secundaria, pues lo verdaderamente importante en la novela de González Sainz es su enfrentamiento a los mitos de una generación, la que ahora frisa los cincuenta años, y sobre todo cómo bajo las coartadas de un proceso político o de una posición ideológica se escondieron problemas psicológicos de autoafirmación, dependencias emocionales, y mecanismos de sustitución que ahondaron fatalmente la sima que Gonzáles Sainz convierte en tema de su novela: la que hay entre las representaciones de trampas del lenguaje y la realidad. Esto es: la ideología es un lenguaje, y progresivamente va abriendo su distancia respecto a la naturaleza, lo sencillo, lo autentico, que representa aquí el mundo arcaico originario de las montañas de Soria y los personajes de Anastasio y el Biercolés. Aunque la novela de González Sainz, muy bien dotada de densidad reflexiva, apunta en una dirección más general y filosófica y tenga como quicio fundamental las dualidades verdad/apariencia, naturaleza/ideología, también es cierto que se concentra en la misma generación que las de David Castillo o Chirbes, y abre un proceso de rendición de cuentas con los mitos que han sostenido la política de los años sesenta y setenta, como si estuviéramos ya en la etapa del balance, lo que se hace en largas conversaciones en que los personajes repasan su juventud, vista desde la lucidez desengañada del presente.

Estamos, según las que llevo analizadas, en condiciones de asediar la que entiendo estructura formal básica de este subgénero temático: la estructura básica es la del presente histórico, es decir, la evaluación que del pasado se hace desde un presente que no sólo asiste a su narración, sino que sobre todo tiende a trazar, desde la elipse de su desengaño, el desenmascaramiento del pasado biográfico de sus protagonistas, desde el presupuesto ideológico de la mayor autenticidad del presente respecto a las mistificaciones heroicas de un pasado, que se entiende como clausurado, cerrado. Esta estructura 
formal nutre otra: suele hacerse desde evaluaciones que hacen los personajes en estilo directo, a menudo en estructura dialogística. Sea con alguien que indaga desde fuera, intentando acceder a la verdad (González Sainz), sea con un proceso coral (Chirbes), lo cierto es que la modalidad predominante es la del estilo directo y focalización interna. Son los propios personajes los narradores, o al menos los focalizadores de una estructura que en el marco memorialístico conoce el soporte estructural básico de la tradición confesional o examen de conciencia. Esta estructura formal favorece una conclusión de fin de ciclo: la Historia concebida como soporte ideológico en que se concreta la lucha colectiva de una generación ha terminado, y estamos en condiciones de decir ahora su sentido, a menudo con la conclusión desengañada, netamente posmoderna, si no en el ámbito concreto de la políticas de la nostalgia, sí en el del desencanto.

Ésta es asimismo la dominante de dos novelas muy diferentes en tono y en temática, pero no en su estructura formal básica, publicadas en el 2004: Castillos de cartón de Almudena Grandes y El hijo del acordeonista, de Bernardo Atxaga. La trama propiamente amorosa de la última novela de Grandes es un mero soporte para narrar la historia de un desencanto, el final de una época y de un tipo de vida, construido en la alegría de la transición democrática española, y que se ha emblematizado comúnmente con el sustantivo movida, en el Madrid del alcalde Tierno Galván, en los primeros años ochenta del pasado siglo. En la página 74 de la novela se ofrece el que considero texto clave que actúa como marco de su trama:

Estábamos en 1984, teníamos veinte años, el mundo todavía caminaba hacia delante, Madrid era el mundo y yo estaba en medio, dispuesta a tragármelo sin tomarme la molestia de masticar antes cada bocado. Diez años antes aquella escena no habría podido suceder. Diez años después habría sido igual de imposible. Pero estábamos en 1984 y teníamos veinte años, Madrid tenía veinte años, España tenía veinte años y todo estaba en su sitio, un pasado oscuro, un presente luminoso y la flecha que señalaba en la dirección correcta hacia lo que entonces creíamos que era el futuro. Aquel fue nuestro riesgo y nuestro privilegio.

Privilegios y riesgos en una aventura amorosa presidida por el número tres, un número que llena toda la novela, no el convencional trío, sino otro, el de un amor y una sexualidad antisistema, liberada de sus ataduras. La narradora va pautando al comienzo de cada capítulo las posibilidades del número tres y su difícil relación con el dos, que es el número de la pareja. La narradora nos va introduciendo primero en el alborozo del descubrimiento, en la pasión de una inocencia no pervertida, pese a la rareza de la relación que entabla María José con Jaime y Marcos, para ir midiendo luego, paso a paso, las sombras que se ciernen sobre esa relación, una vez el fantasma de los celos, los amorosos y sobre todo los profesionales, la van acechando y cercenando. El lector ya conoce desde el principio el final desgraciado de la historia, que se desarrolla en un habilísimo flash back. Pero se trata de explicarlo, de contarlo. Si tuviera que referirme a una analogía para señalar dónde se encuentra la clave de su acierto, tendría que apelar al teatro. Esta novela, en efecto, es muy teatral, rige una trama con planteamiento, nudo y desenlace, pero que se vive por tres personajes en la soledad de sus debates internos, sin apenas mundo exterior a ellos, en el declive de sus ilusiones y en el desmontaje de sus castillos de cartón. Bien elegido título para la significación de un drama que se vive dialécticamente, en una lucha de los tres con los tres y de cada uno de ellos consigo mismo. 
En la novela cobran importancia los señalados contextos de una juventud de los ochenta viviendo las etapas de una utopía liberadora, también en el orden social y sexual, que ahora viene a clausurarse, porque todo se narra desde un presente, en la noticia de la muerte de Marcos, y como una reconstrucción de aquello que no pudo ser, y ya no es definitivamente.

Otra vez la estructura formal básica que venimos recorriendo y que nutre también la compleja novela de Bernardo Atxaga, El hijo del acordeonista. Vuelve Atxaga a Obaba, pero con una obra de intención y factura muy diferente a la que abrió ese mundo narrativo, Obabakoak, que le situó con justicia en la primera fila de la narrativa vasca de hoy y le hizo conocido y muy leído en sus traducciones a lenguas diferentes del euskera. Obaba, la aldea originaria que se transmuta aquí en Iruain, Lecuona y alcanza una geografía precisa, es ahora el espacio recuperado para contar la historia de una generación de jóvenes vascos, desde los años sesenta, con retrospectivas que alcanzan asimismo hasta el nacimiento de ETA, y los primeros pasos de un comando de la banda, en los últimos días de la dictadura de Franco y el comienzo de la transición.

El marco de la novela nos sitúa en el momento actual, puesto que la novela arranca y se cierra en un rancho de California donde vive el protagonista, David Imaz, enfermo, cansado y en trance de saldar su pasado con la escritura de las memorias que el lector está leyendo. Alguna retrospectiva y singularmente una novela corta inserta, titulada «El primer americano de Obaba», una pequeña obra maestra del género, permiten llevar al lector a los primeros momentos de la guerra civil de 1936, puesto que la guerra civil y especialmente el bombardeo de Gernika van a ocupar un lugar de privilegio en el esfuerzo de Atxaga por explicar que los orígenes de esa bola de acero del terrorismo, ahora a la deriva y con enloquecidos estertores, tuvo orígenes vinculados a la lucha contra la dictadura fascista, según explica un personaje en una lectura pública (Atxaga 2004: 441).

Se trata, sí, de explicar, pero también de cerrar un ciclo narrativo y un ciclo histórico, que ya había Atxaga adelantado en su formidable novela El hombre solo (1995). La que ahora nos ocupa es ambiciosa y está meticulosamente elaborada, muy cuidada, porque su autor conoce la dificultad de escribir hoy la novela de ETA. La estructura de esta novela le permite, mediante unas inteligentes y medidas elipsis, ofrecer esa historia como un pasado, incluso reconociendo en la poética inserta en las páginas finales (y explícitamente en la página 480) «que la realidad es triste y que los libros, hasta los más duros, la embellecen». Y no creo que se trate solamente de teoría literaria, o de una reflexión sobre la escritura de ficciones; la medida la da a mi juicio que ese embellecimiento tenga que ver con otra frase de la novela, unas páginas atrás: «parece que no hay manera de librarse del pasado. Sacamos la mosca de la sopa y en cuanto nos descuidamos la tenemos ahí otra vez» (Atxaga 2004: 443). Es magnífica la rememoración de los espacios infantiles, el paisaje de los bosques y el río, ese mundo rural primitivo, no hollado; también está muy bien dosificada la lucha con el padre y con su pasado. Resulta muy inteligente el conjunto de la estructura narrativa al permitir que los flash back, los saltos hacia delante y hacia atrás desde el pivote narrativo que sitúa el marco en un momento de hoy y en un espacio alejado, un rancho americano, hagan coincidir la estructura de la obra con el propósito de rendición de cuentas con el pasado que la historia misma propone, y que encuentra su cenit en la feliz 
inserción de las tres paralelas confesiones de desengaño de los tres jóvenes del comando etarra con las que la novela se cierra.

El llamado fin de la Historia con el que se abrió un ciclo de nuestro presente, es mucho más que una proclama neoliberal, coincidente por otra parte con otros diagnósticos sobre el fin de la modernidad; es la estructura básica que anima el sentido y la forma de una parte muy representativa de la novelística española de comienzos de siglo: un modo de leer el pasado desde el presente, con la conciencia implícita de final de un ciclo histórico.

\section{Bibliografía}

ANDERSON, P. (1996): Los fines de la historia. Barcelona, Anagrama. (1998): Los orígenes de la posmodernidad. Barcelona, Anagrama, 1998.

AtXagA, B. (2004): El hijo del acordeonista. Madrid, Alfaguara.

BELL, D. (1976): Vers la societé post-industrielle. Paris, Lafont.

CASTILlo, D. (1999): El cielo del infierno. Barcelona, Anagrama.

ChIRBES, R. (2003): Los viejos amigos. Barcelona, Anagrama.

FuKUYAMA, F. (1989): « The End of History?», The National Interest, 16, pp. 3-18. (1992): El fin de la Historia y el último hombre. Barcelona, Planeta, 1992.

GÁNDARA, A. (2001): Últimas noticias de nuestro mundo. Barcelona, Anagrama, Premio Herralde de 2001.

GonZÁlez SAINZ, J. A. (2003): Volver al mundo. Barcelona, Anagrama.

GRANDES, A. (2004): Castillos de cartón. Barcelona Tusquets.

HABERMAS, J. (1998): «La modernidad, un proyecto incompleto», en Hal FosteR, ed: $L a$ posmodernidad. Barcelona, Kairós, pp.19-36.

Hassan, I. (1982): The Dismemberment of Orpheus. Toward a Postmodern Literature. Madison, University of Wisconsin Press.

Holloway, V. (1999): El posmodernismo y otras tendencias de la novela española (1967-1995). Madrid, Fundamentos.

JAMESON, F. (1991): El posmodernismo o la lógica cultural del capitalismo avanzado. Barcelona, Paidós.

LIPOVETSKY, G. (1987): La era del vacío. Ensayos sobre el individualismo contemporáneo. Barcelona, Anagrama.

LYOTARD, J. F. (1984): La condición posmoderna. Informe sobre el saber. Madrid, Cátedra, 1984.

MARCHAN-FIZ, M. (1986): Del arte objetual al arte de concepto. Epílogo sobre la sensibilidad postmoderna. Madrid, Akal.

RATo, M. A. (2002): Fuga en espejo. Madrid, Alianza. 